\title{
Organic agriculture as a factor in the development of rural tourism in the Sverdlovsk region
}

\author{
A. A. Oshkordina, E. I. Okhrimenko, and N. A. Goncharova \\ Ural State University of Economics, 620144, Yekaterinburg, Russia
}

\begin{abstract}
The authors in the article consider sectoral changes and structural transformations in the field of agriculture associated with the influence of global trends and growth factors in agricultural productivity. One of these trends, the authors identify rural tourism (ecotourism), the development of which increases the socio-cultural, financial and economic level of agricultural areas. The factors of development and implementation of agricultural technologies of organic agriculture, which have a positive effect on the development of rural tourism and form the demand for tourism products, have been identified. The ways of improving the organization and implementation of event and tourist activities as effective tools for attracting attention and popularizing rural areas have been identified, which in the context of the prevention of coronavirus infection around the world is an urgent factor for many categories of the population. In the context of the prevention of coronavirus, infection in many countries, domestic tourism is becoming a priority area for the development of the tourism industry, focusing, among other things, on the development of new products for rural and agro-industrial tourism.
\end{abstract}

\section{Introduction}

As the world practice shows, the agro-industrial complex is the most important, rapidly developing sector of the economy, which determines the economic security of any country. As the head of Rosstat Pavel Malkov noted: "Agriculture is one of the key sectors of the economy. This is economic and food security and this is the independence and confidence in the future of the country. "The development of the Russian agro-industrial complex will be determined by market-significant technologies of the agricultural production process, focused on informatization, automation, robotization and integration of the activities of organizations of various industries and subsectors of the national economy. In modern socioeconomic conditions, the multiplier effect of tourism can make a significant contribution to the development of the economy of rural areas as a factor in additional sources of financial resources, the formation of the social infrastructure of the area, as well as the popularization and enhancement of the cultural, cognitive and patriotic consciousness of the population.

Rural tourism (ecotourism) is not only a certain tribute to the widespread fashion, but also a certain necessity for the urban population living in an unfavorable ecological and psychoemotional environment of the modern and dynamically changing rhythm of life of every city 
dweller. Rest in the countryside allows you to get closer and enjoy nature, combined with an introduction to the historical, cultural and ethnographic aspects of the heritage. Get acquainted with customs, crafts, national cuisine, clothes, etc. the population living in a given territory. In addition, rural tourism can also carry a research orientation in the form of collecting folklore, studying the local language and dialect, collecting plant and mineral raw materials and materials, etc. According to Smirnova I.V. the population, tired of the bustle of a big city, seeks to relax physically, mentally, enjoy the beauty of nature, touch the cultural heritage of historically significant, but not as popular places as in large tourist centers [1].

The purpose of the study is to determine the main directions of the development of ecotourism as a factor in increasing the economic efficiency of the development of agricultural technologies in organic agriculture.

Thus, the territory of our country, including the Sverdlovsk region, has a powerful potential of natural, landscape, climatic, cultural, historical, ethnic and economic resources, which involves the implementation of various kinds of tourism activities in rural areas. At the same time, it should be noted that the implementation of ideas and activities in rural areas is possible only in ecologically clean areas that are not covered by industrial production, polluting the environment in rural areas.

\section{Materials and Methods}

The materials and research base were statistical, accounting and reporting and information sources of the activities of agricultural organizations and enterprises of the tourism industry of the Sverdlovsk region. The materials of scientific research of domestic and foreign scientists in the field of development of rural and agro-industrial tourism were used. When processing and systematizing information and analytical material, the methods of grouping, detailing, synthesis, the historical and logical research method, as well as methods of economic analysis were used.

\section{Results and Discussion}

Based on the study of the information and statistical material of the UN comtrade dadabase databases and industry experts, prepared by the International Independent Institute of Agrarian Policy, 4 groups are distinguished in the trends in the development of high technologies for the next 10 years:

1) demography - an increase in the level of urbanization and population growth, as well as a high level of medical technologies in health care, which increases the life expectancy of the population, causes an increase in agricultural production throughout the world, which will entail an increase in the intensity of production processes while minimizing labor costs;

2) climate and resources - a decrease in land and water resources, environmental degradation, changes in climatic factors cause a reorientation from traditional agricultural technologies to irrigation technologies;

3) market - the globalization of world food trade, the formation of vertically integrated transnational agricultural holdings, the development of legislation governing world food trade;

4) technologies to improve the economic production, social efficiency of agricultural production [2].

In the 70s of the last century, technologies of organic agriculture are being introduced into the agro-industrial complexes of economically developed countries, involving the organization of a social-production system with a focus on maintaining the health of the population, ecology, soil and food. Since this time, the volume of sales of organic 
agriculture products has tended to increase steadily and by 20012 reached $\$ 63$ billion worldwide. This demand led to a similar increase in organic farmland, which increased by $8.9 \%$ from 2001 to 2011 . Annually [3].

By 2019, more than 70 million hectares on Earth are used in accordance with the principles of organic agriculture, which is approximately 1.4 percent of the total agricultural land in the world [4]. Moreover, more than half of this volume is accounted for by Australia [5]. Since 2015, the world market for organic products has been steadily increasing on average by about $15 \%[6]$.

According to the Union of Organic Agriculture, the main incentives for the development of organic production are: public health $(24 \%)$, high added value $(27 \%)$, environmental improvement (22\%), personal health (15\%), humanitarian attitude towards animals $(7 \%)$ and other $(7 \%)$ and is currently the most promising direction in the development of agriculture [7]. At the same time, the transition to environmentally friendly agriculture is currently among the priorities of the scientific and technological development of Russia, but it is not happening at a fast enough pace. The Strategy [8] notes the problem of "increasing anthropogenic pressures on the environment to a scale that threatens the reproduction of natural resources, and the increase in risks to the life and health of citizens associated with their ineffective use".

Table 1. Quantitative indicators of the development of the agro-industrial complex of Russia [9, 10]

\begin{tabular}{|c|c|c|c|}
\hline Indicators & $\begin{array}{c}2002 \\
\text { year }\end{array}$ & $\begin{array}{c}2012 \\
\text { year }\end{array}$ & $\begin{array}{c}2020 \\
\text { year }\end{array}$ \\
\hline Number of agricultural organizations, thousand & 253,1 & 140,6 & 41,9 \\
\hline Number of peasant farms and individual entrepreneurs, thousand & 32,8 & 39,0 & 144,9 \\
\hline Number of non-profit associations and societies, thousand & 79,8 & 76,3 & 80,4 \\
\hline Number of subsidiary farms, million & 22,6 & 18,2 & 16,5 \\
\hline $\begin{array}{c}\text { The share of products produced on personal subsidiary plots of } \\
\text { the total agricultural production,\% }\end{array}$ & 53,8 & 43,2 & 28,2 \\
\hline $\begin{array}{c}\text { Total area of land plots of personal subsidiary plots, million } \\
\text { hectares }\end{array}$ & 6,2 & 6,9 & 8,0 \\
\hline
\end{tabular}

Within the last two decades, the indicators of table 1 indicate a dramatic reduction in the number of agricultural organizations by more than 5 times against the background of an increase in the number of peasant farms and individual entrepreneurs in almost equal proportion - 4 times, which may be due to factors of the regulatory and tax nature of maintaining accounting and reporting documentation various organizational and legal forms of activity of enterprises of the agro-industrial complex of Russia. Attention is also drawn to a significant change in the structure of agricultural production. So, in 2002, more than half of the total agricultural production fell on personal subsidiary plots, while in 2020 the share of agricultural production was less than $30 \%$ in its total volume. At the same time, it is necessary to note an increase in the area of land plots owned by Russians from 6.2 million hectares to 8 million in 2020 .

The ratio of the indicators under consideration may indicate a decrease in the population's interest in the production of agricultural products with their own hands due to the saturation of the market, as well as the reorientation of the needs of citizens to use homesteads and dacha estates as objects of aesthetic and contemplative rest and entertainment. In addition, the pandemic of coronavirus infection has made its own adjustments to increase the demand for the acquisition of land plots in order to grow crops and food with our own hands due to economic, physiological and environmental factors that can strengthen the body's immune system and increase its resistance in the process of carrying out preventive measures for fight against coronavirus infection. This thesis is confirmed by a member of the State Duma Committee on Economic Policy and Entrepreneurship, Chairman of the Union of Gardeners 
of Russia Oleg Valenchuk, who in his interview reflected the high interest of the population in acquiring abandoned plots in order to grow agricultural products with their own hands. At the same time, Andrey Tumanov, editor-in-chief of the newspaper Vashi 6 sotok, a member of the public council of Rosreestr, urged not to rush into forecasts due to the lack of reliable statistics on this issue, the database of which has not yet been formed over the past 2 years. In addition, Andrei Tumanov noted the high demand for the population of only those land plots that can be capitalized in the future, are distinguished by a high level of transport accessibility, are gasified, that is, absolutely suitable for permanent or temporary residence and recreation, which does not at all imply the goal of collecting a high yield [11 ]. This assumption is indirectly confirmed by the statistical indicators of Table 1, reflecting a decrease in the number of subsidiary farms by more than $30 \%$, as well as a decrease in the share of agricultural products produced on personal subsidiary farms from the total agricultural production by almost 2 times.

Thus, over the past 2 decades, significant structural transformations have taken place in the structure of the agro-industrial complex of Russia, associated with an increase in the number of peasant farms and individual entrepreneurs by almost 5 times, while the number of agricultural organizations has decreased by more. It should be noted a very important factor, which in turn affects the rapid growth of changes and transformations in the field of agriculture - this is a reorientation of consumer preferences associated with an increase in the population's demand for the consumption of environmentally friendly, healthy products, as well as cultural, entertainment and contemplative pastime in the bosom nature in rural areas with the aim of improving the effect of the psychoemotional state of a person. In addition, today, uniform approaches to taste preferences and global brands and brands are gradually becoming outdated, yielding to the formation of demand for regional, local products that reflect the cultural and historical heritage of a given territory. At the same time, an urgent approach to the formation of a healthy lifestyle and the prevention of many diseases with the use of occupational therapy technologies in ecologically safe agricultural areas is also increasingly important. Therefore, ecotourism today is becoming an increasingly popular trend not only in Russia, but also in other economically developed countries.

The territory of the Sverdlovsk Region was formed on January 17, 1934 and is located on the border of Europe and Asia at the intersection of transcontinental flows of raw materials, goods, financial, labor and information resources. The Sverdlovsk Region today is a large economically developed territory of Russia with a high level of business, cultural and social activity, one of the most promising subjects of the Russian Federation. According to official statistics, the resident population of the region at the beginning of 2021 is 4 million 290 thousand people, of which $85 \%$ is urban population, and only $15 \%$ of the population of the total population of the region is rural residents, which once again confirms the high level of urbanization and the uneven ratio of urban and rural populations. On the territory of the Sverdlovsk region there are 47 cities, 26 workers' settlements and urban-type settlements, 1804 rural settlements [12]. Despite the harsh climatic features, agriculture is rapidly developing in the Sverdlovsk region. Therefore, at the beginning of 2021, 350 agricultural organizations are carrying out production and economic activities, about 800 peasants and farms and entrepreneurs, about 419 thousand citizens have personal subsidiary plots. Thus, on the territory of the Sverdlovsk region. According to the latest data in the Sverdlovsk region, more than 818.0 thousand hectares are allotted for sown areas for agricultural crops. By industry, the average annual number of employees as of 01.01.2020 is: in agriculture 51,524 people, in fish farming and fishing - 217 people, in food production - 32,566 people, in the production of drinks - 2837 people. Thus, according to the main socio-economic development criteria, the Sverdlovsk Region is included in the top ten regions of the Russian Federation. In addition, the socio-cultural infrastructure formed on the territory of the region allows many rural areas to implement event, sports and tourist events. 
Analyzing the information and analytical material of the Tourism Development Center of the Sverdlovsk Region on the implementation of event activities in rural areas and settlements, one can identify a rather low level of activity among the population and rural administrations. So, in 2021, more than 370 events of various orientations were planned, from cultural, ethnic and religious to sports, entertainment and educational. Only 31 events of an eventful nature were implemented in the rural areas of the Sverdlovsk region, which amounted to about $8 \%$ of their total number. At the same time, it is necessary to note as a positive trend the annual increase in the implementation of projects in the field of event events, as well as the formation of new products of rural, eco and gastronomic tourism, which indicates an increase in consumer demand and the involvement of an increasing number of rural settlements in the tourism industry. At the same time, it is necessary to note the fact of expanding the range of tourist products. So, for example, in the Artinsky district, the Festival of Mowers in July is already righteous 12 times, the festival "Valenok 21" was held for the first time, and also in 2021, in July, the participants of the motocross celebrated the sixth anniversary, and this year the motocross was held for the first time and in the winter period ... The following events can be noted as positive examples: Motocross in memory of B.F. Zefirova in the village of Melnikova; the massive descent "Avalanche" in the village of Uralets; "Maslenitsa" and "Trinity Festivities" in the villages of Pokrovskoye, Chernoskutovo, Kadnikovo; competition "Dog Race" in the village of Visim; "Georgievskaya Fair" in the village of Mironovo; Festival "Broad Cossack Prowess" and "Sabantuy" - a bright and colorful holiday that contributes to the development of national cultures, strengthening the friendship of peoples in the settlements of Lesnoy and Novaya Lyalya; Festival Lyalinskoe Porechye "; Festival "Konzhakovsky chord" in the village of Kytlym; in the picturesque area of the village of Kashino, a holiday dedicated to the Day of Family, Love and Fidelity is taking place. At the central site of the Kashinsky Round Dance, newlyweds are honored and an old wedding ceremony is held. Creative teams perform here and various competitions are held; Festival "Park of National Cultures" The village of Bulanash is a multinational settlement where representatives of 30 national cultures live; "Demidov - fest" in the village of Chernoistochinsk; the Visimsky picnic gastronomic festival, restoring forgotten recipes of the Ural cuisine and rediscovering the Ural culinary brands; Semeonovskaya fair in the village of Raskat; Stone festival "Samotsvetnaya side" in the village of Murzinka; Festival "At the outskirts" in the village of Kordyukovo; Fair "Krasnogorsk torzhok" in the village of Krasnogorskoe; Birthday of Ural Moroz in the village of Aramil and others.

If we talk about the degree of active participation in event activities of all rural areas of the region, then we have to state a sad fact: only about 30 rural settlements of the region out of 1804 take any part in the organization and implementation of tourism activities, which, first of all, indicates a low level of interest, both the rural population itself and the leading personnel of rural administrations and agricultural enterprises. At the same time, in recent years, the government of the Sverdlovsk Region has provided organizers of events in sparsely populated cities and rural areas with a unique opportunity to apply for financial, organizational and legal support free of charge.

One cannot ignore the young unique project in the village of Mramorskoye "Day of Marble Music" within the framework of the "Marble Mile" project, which was successfully launched in 2019 with the support of the Idea Social Activity Fund. Another unique project, known for over 40 years and attracting the attention of tourists not only of the Sverdlovsk region, but also guests from other regions "Nizhnyaya Sinyachikha and the Museum-Reserve of Wooden Architecture". Moreover, attention is drawn to the fact that the implementation of this project was initiated by one and only person, Ivan Danilovich Samoilov. To date, a stable tourist flow per month has been formed in Nizhnyaya Sinyachikha, averaging 400-500 people. Nizhnyaya Sinyachikha is proof of the possible organization and implementation of 
projects in the presence of personal interest and activity of the local population. Nizhnie Tavolgi is an old Ural village with a population of about 350 people, since ancient times it was famous for its products of pottery. Together with the Upper Tavolga, a center of folk crafts was organized. A modern tourist infrastructure has been created, providing a camphor stay on the territory of these settlements. There have been developed tourist routes of various duration and thematic component. The presence of a tourist social infrastructure makes it possible to hold regional and international festivals, such as the tea eco-festival "When Tavolga Blossoms", the Festival of arts and crafts "Secrets of the Gem Ring", etc. Thus, the territory is actively developing and creates additional jobs through the sale of tourism products and agricultural business.

At the same time, it is necessary to note the fact of the irregular, one-time nature of event events during the entire calendar year, which does not imply an even distribution of tourist flows, which in turn affects the abrupt formation of financial flows (both from the side of income and from the side of expenses) ... In addition to the financial and economic component, one should not forget about the formation of cultural, ethnic and cognitive functions in the implementation of event and tourist activities. So, in most of the above-listed settlements, creative and amateur groups, circles and creative communities are being created that are interested in observing local culture, traditions, customs, religious beliefs, as well as studying the historical aspects of the development of the territory of their place of residence. This undoubtedly increases the level of involvement in the creative process of children and adolescents, forming from an early age love for their small homeland, patriotism, craving for knowledge in all spheres of human life, as well as acquiring skills in the production of folk art items, souvenirs and agricultural products.

In the formation of regular flows of eco-tourists to the countryside, the production of organic agricultural products plays a vital role, which is becoming increasingly popular among the population of all countries of the world. A person wants to consume environmentally friendly, natural products, as well as study the process and recipe for cooking food and folk art. For these purposes, many farms organize short-term and long-term stays in rural areas and in many constituent entities of the Russian Federation, financial resources are allocated in the form of grant support. The Sverdlovsk region cannot boast of the rapid introduction of such tourist products and today only 7 organizations have been organized in the region, these include: Reindeer Nursery "Northern Lights", VerkhnePyshminsky District; "GreenPoll" in the Gornouralsky urban district, the village of NikoloPavlovskoye; sled dog kennel "Elbrus" in the village of Medny; the first eco-farm "Harmony" in the region in the village of Bolshebrusyanskoye, which produces and sells products of organic agriculture; the eco-farm "Valley of the goats" in the village of Parshino, which implements weekend gastronomic tours, where you can actively relax, caring for animals, get acquainted with the intricacies of cooking dishes from animal and plant products, contemplate the beauty of the Ural nature and take part in contests and quizzes; A sturgeon farm in the village of Kosulino, which successfully implements gastronomic tours with the participation of tourists in the preparation of national dishes of the Ural cuisine; The Slavyanskoe Gnezdo eco-farm, which opened in July 2021, in the village of Beklenishcheva, where you can taste traditional dishes of the Ural cuisine and get acquainted with the oriental recipe of camel milk dishes.

Studying the reviews of tourists who used the services of eco-farms and nurseries of the Sverdlovsk region, it is necessary to note the high marks of the organization and implementation of these tours. In addition, eco and gastronomic tours are focused on all age groups of the population and, above all, on family vacations, where both children and adults 
are involved in the production of agricultural products, which undoubtedly also affects the formation of family values in society and makes the vacation unforgettable.

\section{Conclusion}

In the modern socio-economic conditions of the development of rural areas, a certain role can be played by the organization and sale of products of rural and gastronomic tourism. At the same time, the share of agritourism in the Russian tourist market does not exceed $2 \%$. The presence of a huge variety of climatogeographic, natural, cultural-ethnic, historical resources of rural areas of Russia, including the Sverdlovsk region, has the ability to organize and introduce tourism products with a high degree of competitiveness, which in turn will allow solving various problems and problems of social and economic and cultural nature in rural areas. At the same time, rural tourism today has not received a mass character on the territory of Russia, but is so-called point distribution and is directly proportional to the activity and initiative of the local population and rural administrations. However, the implementation of ideas and projects of rural tourism requires support from the government.

Despite the dynamically developing rural tourism on the territory of the Russian Federation, in recent years, there are serious problems in the industry that require immediate solutions. So, according to I.L. Polyakova and M.P. Grigorieva. The state of rural tourism in Russia and its development trends allow us to single out a number of factors that hinder its further development:

- insufficient support for rural tourism as a separate branch of the economy;

- undeveloped legislative and regulatory framework;

- lack of a comprehensive system of incentives for rural tourism activities;

- poorly developed tourist infrastructure, including the transport system;

- the low standard of living of the rural population of the Russian regions;

- insufficiently effective mechanism for managing the rural tourism sector;

- unfavorable climatic conditions;

- terrorism, criminal situation;

- insufficiently developed infrastructure of rural areas;

- weak system of promoting and informing agricultural products in the domestic and international markets;

- lack of a recognizable brand;

- low level of investment in the development of rural tourism;

- lack of support programs for rural areas [13].

To solve these problems, in our opinion, it is necessary:

- development of regulatory documents regulating tourism activities at all stages of its implementation, taking into account the specifics of the functioning of economic entities in rural areas;

- development of regional target programs focused on financial support of current ideas and projects for the organization of rural tourism;

- attraction of financial resources of private organizations and investors on a preferential or gratuitous basis;

- raising the level of awareness about the possibility of participation of the population in various events in rural tourism through the mass media;

- update the development of short-term weekend tourist products using elements of event tourism (hiking, making organic products and folk art items with your own hands, engaging in agricultural work, collecting medicinal herbs, making agricultural products, etc.);

- popularization of themed corporate events, weddings, banquets, children's parties, etc. on the territory of agricultural enterprises. In our opinion, the set of measures developed will increase the scale of the spread of ecotourism in rural areas, as well as increase the speed of 
their popularization among the population. In modern conditions of development of rural areas, agritourism should be perceived as an effective economic tool for their development from various aspects of activity.

\section{References}

1. I.V. Smirnova, Bulletin of the Mari State University, 1(13), 87 (2014)

2. Global Seed. Organic farming (2021) http://www.globalseed.info

3. J. Paull, Journal of Social and Development Sciences, 2(3), 111 (2011)

4. The World of Organic Agriculture 2019. FiBL and IFOAM (2019)

5. J. Paull, Journal of Environment Protection and Sustainable Development, 5(2), 70 (2019)

6. A. N. Anischenko, Food policy and security, 2, 97 (2019)

7. Organic agriculture: innovative technologies, experience, prospects. / scientific. analyte. Overview, 92 (2019)

8. Strategy of scientific and technological development of the Russian Federation (approved by the Decree of the President of the Russian Federation of December 1, No. 642) (2016)

9. Dyatlovskaya E. Rosstat published the first operational results of the agricultural census 2016. Agroinvestor (2016) https://www.agroinvestor.ru

10. E. Manukyan, In Rosstat told about the tasks of the agricultural census in 2021. Russian newspaper (2021) https://rg.ru

11. Yu. Ignatieva, Pitchfork on the ground: what the last microcensus will show. Izvestia. (2021) https://iz.ru

12. Official site of the government of the Sverdlovsk region (2021) http://midural.ru

13. I.L. Polyakova, M.P. Grigorieva, Service in Russia and abroad, 11(5), 31 (2017) 